University of Nebraska - Lincoln

DigitalCommons@University of Nebraska - Lincoln

Sociology Department, Faculty Publications

Sociology, Department of

2-4-1977

\title{
Comments on Jackman's "Political Elites, Mass Publics, and Support for Democratic Principles"
}

Louis St. Peter

University of Nebraska-Lincoln

J. Allen Williams Jr.

University of Nebraska-Lincoln, jwilliams2@unl.edu

David R. Johnson

University of Nebraska-Lincoln, drjlks@yahoo.com

Follow this and additional works at: https://digitalcommons.unl.edu/sociologyfacpub

Part of the Sociology Commons

St. Peter, Louis; Williams, J. Allen Jr.; and Johnson, David R., "Comments on Jackman's "Political Elites, Mass Publics, and Support for Democratic Principles"'" (1977). Sociology Department, Faculty

Publications. 1.

https://digitalcommons.unl.edu/sociologyfacpub/1

This Article is brought to you for free and open access by the Sociology, Department of at DigitalCommons@University of Nebraska - Lincoln. It has been accepted for inclusion in Sociology Department, Faculty Publications by an authorized administrator of DigitalCommons@University of Nebraska - Lincoln. 


\section{Comments on Jackman's \\ "Political Elites, Mass Publics, \\ and Support for \\ Democratic Principles"}

Louis St. Peter

J. Allen Williams, JR.

David R. Johnson

W

HEREAS CLASSICAL POLITICAL THEORY indicates that widespread public support for democratic principles is necessary for the maintenance of a democratic society, research evidence has almost universally shown a difference between the general public and the elite with the latter being more supportive. ${ }^{1}$ Many contemporary observers, in contradiction to classical theory, have explained this

- The authors woud like to thank Susan Welch for her valuable comments on an earlier draft of this paper.

${ }^{1}$ Classical political theory, in various forms, has had such a wide and longstanding acceptance that it would be impractical to cite the literature. However, one frequently cited and comprehensive discussion is Ernest S. Griffith, John Plamenatz and J. Roland Pennock, "Cultural Prerequisites to a Successfully Functioning Democracy: A Symposium," American Political Science Review, 50 (March 1956), 101-137. Empirical studies showing mass-elite differences include Samuel A. Stouffer, Communism, Conformity, and Civil Liberties (New York: Doubleday, 1955); and Herbert McClosky, "Consensus and Ideology in American Politics," American Political Science Review, 58 (June 1964), 361-382. 
difference in terms of an independent politically active stratum, differing from the mass public not only in terms of generally higher social status, but also by a unique socialization process. ${ }^{2}$ An article published in the Journal of Politics by Robert Jackman has challenged this interpretation by purporting to show that when education and other relevant variables are controlled, leaders are no more tolerant than are members of the mass public. ${ }^{3}$ His conclusion:

Clearly, there is little evidence here for the possible existence of special attitudes belonging to a distinctive political stratum because we have no residual category that requires labeling. As a result, theories that attempt to account for the differential rates of support for minority rights among elites and the mass public by invoking the notion that elites undergo some unique resocialization process are basically superfluous. ${ }^{4}$

Recently, we discovered an error in Jackman's analysis. A correction of that error leads to a conclusion exactly opposite from his.

Jackman reanalyzed data collected by Samuel Stouffer which sampled attitudes of both the mass public and selected community leaders. ${ }^{5}$ The dependent variable is a scale based upon fifteen questions concerned with attitudes toward civil liberties. On this scale, which has a possible range from 0 (low tolerance) to 100 (high

2 Perhaps the first major statement expressing this view is Bernard Berelson, Paul Lazarsfeld and William N. McPhee, Voting (Chicago: University of Chicago Press, 1954). More recent statements include William Kornhauser, The Politics of Mass Society (New York: Free Press, 1959); V. O. Key, Jr., Public Opinion and American Democracy (New York: Alfred A. Knopf, 1961); Robert A. Dahl, Who Governs? (New Haven: Yale University Press, 1961); and Lester W. Milbrath, Political Participation (Chicago: Rand McNally, 1965).

${ }^{3}$ Jackman's article was published in this Journal, 34 (August 1972), 753-773. Alford and Scoble preceeded Jackman in attempting to test the validity of the pluralist position, but their findings did not eliminate a mass-elite difference in attitudes. However, their findings do show that education has a greater effect on attitudes than leadership. See Robert R. Alford and Harry M. Scoble, "Community Leadership, Education, and Political Behavior," American Sociological Review, 33 (April 1968), 259-272.

4 Jackman, "Political Elites," 766.

${ }^{5}$ Stouffer, Communism, Conformity, and Civil Liberties, used two national probability samples obtained in 1954 , one by the National Opinion Research Center and the other by the American Institute of Public Opinion. Jackman used only the NORC sample which contains 2,450 cases. NORC and AIPO also collected data from samples of selected community leaders in American cities ranging in size from 10,000 to 150,000 population. Jackman used both of these samples for his leaders, a total of 1,500 cases. 
tolerance), leaders have a mean score of 74.8 and the public's score is 56.8. If this difference is eliminated after controlling for social and demographic characteristics, then a distinctive political stratum does not exist. In other words, elimination of the difference would show that leaders simply represent the views of the social strata from which they come. If a difference persists, then a unique political stratum remains a viable possibility.

Mean levels of tolerance were examined within educational categories after adjusting for differences in sex and region through dummy variable regression analysis. City size was held constant in the mass sample. Jackman's conclusion was based upon his finding that differences between tolerance means for leaders and the public within categories of education were small and not consistently higher for either group. This finding, however, is based upon an error in applying the regression methodology which obviates the comparability of the derived means for the mass and elite samples.

A complication, and Jackman's error, arises when we include more than one independent variable in the regression equation each represented by a set of dummy variables. ${ }^{6}$ Each independent variable in the regression will be represented by one less dummy variable than it has categories; one of the categories being omitted. Since the regression weights for each dummy variable represent the deviation from the constant term, the constant must serve as a reference point for all independent variables and is no longer the mean value for respondents in the omitted category. Rather, it represents the additive estimate of the mean for respondents falling into the

${ }^{6}$ For those less familiar with this method of analysis it should be pointed out that in dummy variable regression analysis, categories of the independent variables are each treated as a separate binary variable (coded 1 if the respondent possesses the characteristic, otherwise coded as 0). Each independent variable is represented by one less binary (or dummy) variable than there are categories in the variable, one category being excluded. The unstandardized regression weights of each dummy variable estimates the mean difference on the dependent variable between respondents possessing the characteristic measured by the dummy variable and those possessing the characteristic corresponding to the excluded category. When only one independent variable is analyzed, represented by one less dummy variable than it has categories, then the constant term in the regression equation (the $a$ coefficient) is the mean score for respondents in the omitted category. If the regression weight associated with one of the categories represented by a dummy variable is added to the constant term, this value then estimates the mean on the dependent variable for respondents in that category. 
omitted category of all of the independent variables. ${ }^{7}$ To illustrate, Table 1 shows the estimates of the regression equations for the mass and elite samples presented by Jackman. With these equations we can estimate the tolerance score of persons in any combination

\section{TABLE 1}

Regression Coefficients for the Mass and Elite Samples AS REPORTED BY JACKMAN*

\begin{tabular}{llrr}
\hline & & Mass & Elite \\
\hline $\mathrm{a}$ & Constant term & 86.78 & 85.06 \\
$\mathrm{~b}_{4}$ & Some college & -7.58 & -7.59 \\
$\mathrm{~b}_{3}$ & High school graduate & -15.61 & -11.24 \\
$\mathrm{~b}_{2}$ & Grades $9-11$ & -20.41 & -15.39 \\
$\mathrm{~b}_{1}$ & Grades $0-8$ & -28.09 & -22.28 \\
$\mathrm{c}$ & South & -10.54 & -7.74 \\
$\mathrm{~d}$ & Women & -5.16 & -7.82 \\
$\mathrm{e}_{1}$ & Farm & -8.30 & - \\
$\mathrm{e}_{2}$ & City less than 2,500 & -8.66 & - \\
$\mathrm{e}_{3}$ & City 2,500 to 100,000 & -6.20 & 1,500 \\
$N$ & & 2,450 & \\
\hline
\end{tabular}

" Jackman, "Political Elites."

of categories of the independent variables by adding together the regression weights associated with the categories they are in and adding those to the constant term. The estimated score with this additive regression model for a college educated male, not living in the South, and residing in a city of 100,000 or more population would be 86.78 in the mass sample, the value of the constant term, as each of these characteristics was not represented by a dummy variable. We find by looking at Table 2 that this is identical to the value Jackman gives for the tolerance score of persons with a college degree controlling for region, sex and city size. Jackman has controlled for the three additional variables by presenting the expected means for non-southern males in cities of 100,000 or more population in each educational category. Since he used the same pattern of omitted categories in the leader sample (for the two control vari-

${ }^{7}$ See references cited in Jackman, "Political Elites," footnote 27 and Jerry L. Miller and Maynard L. Erickson, "On Dummy Variable Regression Analysis: A Description and Illustration of the Method," Sociological Methods and Research, 2 (May 1974), 409-430. 
TABLE 2

Expected Tolerance Scones for Categories of the Independent Variables Based on an Additive Regression Model for the Mass and Elite Samples

\begin{tabular}{|c|c|c|c|c|c|c|c|}
\hline Education & $\begin{array}{l}\text { Non- } \\
\text { southern } \\
\text { males in } \\
\text { cities } \\
\text { over } \\
100,000 \\
\text { (Mass)a }\end{array}$ & $\begin{array}{l}\text { Non- } \\
\text { southern } \\
\text { males in } \\
\text { cities } \\
2,500 \text { to } \\
100,000 \\
\text { (Mass) }\end{array}$ & $\begin{array}{c}\text { Non- } \\
\text { southern } \\
\text { males in } \\
\text { cities } \\
10,000- \\
150,000 \\
\text { (Elites)a }\end{array}$ & $\begin{array}{l}\text { Southern } \\
\text { males in } \\
\text { cities } \\
2,500 \text { to } \\
100,000 \\
\text { (Mass) }\end{array}$ & $\begin{array}{c}\text { Southern } \\
\text { males in } \\
\text { cities } \\
10,000- \\
150,000 \\
\text { (Elite) }\end{array}$ & $\begin{array}{c}\text { Non- } \\
\text { southern } \\
\text { females } \\
\text { in cities } \\
2,500 \text { to } \\
100,000 \\
\text { (Mass) }\end{array}$ & $\begin{array}{c}\text { Non- } \\
\text { southerm } \\
\text { females } \\
\text { in cities } \\
2,500 \text { to } \\
100,000 \\
\text { (Elite) }\end{array}$ \\
\hline College graduate & 86.78 & 80.58 & 85.06 & 70.04 & 77.32 & 75.42 & 77.24 \\
\hline Some college & 79.20 & 73.00 & 77.47 & 62.46 & 69.73 & 67.84 & 69.95 \\
\hline High school graduate & 71.16 & 64.96 & 73.72 & 54.42 & 65.98 & 59.80 & 65.90 \\
\hline Grades $9-11$ & 66.37 & 60.17 & 69.67 & 49.63 & 61.93 & 55.01 & 61.85 \\
\hline Grades 0-8 & 58.69 & 52.49 & 62.78 & 41.95 & 55.04 & 47.33 & 54.96 \\
\hline
\end{tabular}

- Taken from Table 2 in Jackman, "Political Elites." 
ables used in both samples, sex and region), he is comparing public with elite non-southern males in each educational category. However, the elite sample is drawn only from cities of 10,000 to 150,000 , which is why Jackman did not control for city size in the leader sample. Since the estimated scores from the mass sample are based upon respondents in cities of 100,000 or more, the comparison with leaders from smaller cities does not adequately control for the effects of city size distribution differences between the two groups. Respondents in the mass sample living in cities from 2,500 to 100,000 would be more comparable with the populations from which the leaders are drawn. As shown in Table 2, in addition to reproducing the expected means derived by Jackman, we have derived the mass sample tolerance means in each educational category for nonsouthern males in cities with populations from 2,500 to 100,000 . When we compare the expected means derived from this segment of the mass sample with those reported by Jackman for the elite sample, it can be seen that leaders have higher tolerance scores in each category of education, especially for those with lower education. This comparison, which is a more reasonable one, clearly contradicts Jackman's conclusion.

Beyond this failure of Jackman adequately to control for city size differences through misuse of the regression procedure, the manner in which he reports adjusted means is subject to misinterpretation. Since non-southern 'males are only one of four possible comparison groups (southern males, southern females, non-southern males, nonsouthern females), it is possible to select comparisons which minimize or maximize mass-leader differences. This also is shown in Table 2 which contains expected scores for both samples for southern males and non-southern females. Non-southern women show the smallest differences within educational categories while southern men show the largest mass-elite differences. In all cases, however, leaders tend to be more tolerant than their counterparts in the general public. ${ }^{8}$

The difficulty in the procedure used by Jackman, even after correcting for the city-size discrepancy, is that it does not give an overall measure of whether the observed difference in tolerance between

8 Table 2 shows appropriate mass-elite comparisons with the largest and smallest differences. Hence, appropriate comparisons not included in the table also show elites having a higher tolerance score. 
leaders and the public is due to differences in their distributions on education, sex, region, and city size. However, there are dummy variable regression procedures which can be used to answer this question.

By combining the mass and elite samples it is possible to estimate a single regression equation. Several procedures can be used to estimate the regression equation, but two appear to be the most appropriate for the present problem. One method is to create a new dummy variable, referred to here as "sample," by coding leaders as 1 and members of the mass public as 0 . Thus, being a leader or a member of the mass becomes an independent variable and education, sex, region, and city size can be treated as control variables. When all of the variables are included in the regression with tolerance as the dependent variable, the unstandardized regression weight of the binary variable, indicating "sample," will be the difference in mean tolerance between those in the mass and elite samples after controlling for the additive effects of the other variables. This regression weight can then be used to estimate a mean score for the mass and elite that adjusts for differences in the two samples in their distributions on sex, region, city size, and education. This is done by assuming that the distribution for each sample on these variables is the same as the distribution in the samples combined. The results using this procedure are presented in Table 3. As shown, a statistically significant difference between the

TABLE 3

Unadjusted and Adjusted Tolerance Scores for Mass and Elite When Samples Have Been Combined

\begin{tabular}{lcc}
\hline & $\begin{array}{c}\text { Unadjusted } \\
\text { Mean }\end{array}$ & $\begin{array}{c}\text { Adjusted } \\
\text { Mean }\end{array}$ \\
\hline Mass & 56.8 & 61.2 \\
Elite & 74.8 & 67.6 \\
\hline
\end{tabular}

* Adjusted for education, region, sex, and city size. The difference between mass and elite adjusted means is statistically significant $(\mathrm{P}<.001)$.

elite and mass remains after eliminating the effects due to education, sex, region, and city size.

A second method, more closely approximating Jackman's approach, uses a series of dummy variables to represent the interaction 
between education and belonging to the elite or mass public. ${ }^{9}$ Since education has five categories and "sample" two (mass or elite), this interaction will be represented by nine dummy variables. When these are entered into the regression equation along with the control variables, the unstandardized regression weights of each of the nine dummy variables will represent the mean differences in tolerance between that particular category of education and "sample" and the missing category of education and "sample." Adjusted mean tolerance scores can be computed for the educational categories of the public and leader samples controlling for sample differences in other variables. Table 4 shows the unadjusted and adjusted mean

\section{TABLE 4}

Unadjusted and Adjusted Tolerance Scores for Mass and Elite by Education When Samples Have Been Combined

\begin{tabular}{lccccc}
\hline & \multicolumn{2}{c}{ Unadjusted Means } & \multicolumn{3}{c}{ Adjusted Means` } \\
Education & Mass & Elite & Mass & Elite & Difference \\
\hline College graduate & 78.5 & 81.7 & 77.7 & 80.7 & -3.0 \\
Some college & 70.0 & 72.0 & 69.1 & 73.0 & -3.9 \\
High school graduate & 62.1 & 70.1 & 61.1 & 69.2 & -8.1 \\
Grades 9-11 & 55.7 & 66.2 & 56.2 & 65.3 & -9.1 \\
Grades 0-8 & 46.8 & 59.8 & 48.4 & 58.8 & -10.4 \\
\hline
\end{tabular}

- Adjusted for region, sex, and city size.

tolerance scores obtained through this procedure. The findings show that mass-elite differences in tolerance within educational categories remain after adjusted for sample differences in sex, region, and city size. Table 4 shows that decreasing educational attainment does not have as great an effect on tolerance scores among the elites as among the mass. An analysis of covariance test of the mass-elite differences in the effect of education on tolerance found it to be statistically significant $(\mathrm{p}<.01)$. In other words, if one interprets this finding within the framework of the theory of political socialization, this statistically significant interaction suggests that the effect of participation as a civic leader on tolerance is greater among those entering the elite from lower educational backgrounds.

${ }^{9}$ For example, one dummy variable would represent college-educated mass and another would represent college-educated elite. 
Both methods of reanalyzing the data used by Jackman yield a leader-mass difference in tolerance. However, it should be emphasized that this neither proves the existence of a distinctive political stratum nor of a unique political socialization process. Many potentially relevant components of the nation's social-stratification system remain uncontrolled in this analysis. And, selective recruitment into elite positions provides a plausible alternative to political socialization. ${ }^{10}$ Thorough consideration of these possibilities is beyond the scope of this comment, however. Our primary purpose has been simply to point out that a reanalysis of the data used by Jackman, using correct procedures, leads to a conclusion opposite from his-pluralist theory is not yet superfluous. Present evidence makes the existence of an independent political stratum a likely possibility.

${ }^{10}$ In reference to this idea, Jackman cites Kenneth Prewitt, "Political Socialization and Leadership Selection," The Annals, 361 (September 1965), 96-111. 